\title{
Process training derived from a computer simulation theory
}

\author{
THOMAS G. HOLZMAN, ROBERT GLASER, and JAMES W. PELLEGRINO \\ University of Pittsburgh, Pittsburgh, Pennsylvania 15260
}

\begin{abstract}
Kotovsky and Simon (1973) identified four basic subprocesses in their computer simulation of adult and adolescent performance on Thurstone letter series completion problems. In Experiment I, children from Grades 1 to 6 were pretested on those problems, and then experimental subjects were trained on two of the four processes as an attempt to experimentally support a correspondence between the computer subroutines and human cognitive processes. A posttest administered in the experimental and control conditions revealed a significantly greater improvement for experimental subjects, although both groups made significant gains. The children's distributions of errors were consistent with Kotovsky and Simon's predictions. In Experiment II, children from Grades 3 and 5 took four series completion tests without intervening training. The additional practice was sufficient for Grade 5 subjects to make improvements similar in magnitude to those produced by training. Grade 3 subjects, however, made no gains. These results are related to Tulving and Pearlstone's (1966) distinction between the availability and the accessibility of memory traces.
\end{abstract}

The psychological reality of computer simulations has generally been derived by comparing human protocols with the outputs of the computer program for the given task. While this method provides, in some sense of correspondence, a test of theory, it does not provide the usually accepted form of independent experimental verification. One possibility for experimental work is a training study in which humans are taught to perform the identified component processes. If a computer simulation model has at least approximated the processes utilized by humans in correctly solving a problem, then instructions on these processes should improve the performance of subjects who initially performed poorly on the task. On the other hand, if the subroutines involved are incompatible with the cognitive structures of the human subject, then instruction on the subroutines should either not influence performance or influence it detrimentally. The present study investigated whether a computer simulation model could suggest subroutines that were instructable and whether instruction on these subroutines could facilitate subjects' solutions to the problem task.

A second issue of the study dealt with the emergence

The research reported herein was supported by the Learning Research and Development Center, supported in part as a research and development center by funds from the National Institute of Education (NIE), United States Department of Health, Education, and Welfare. The opinions expressed do not necessarily reflect the position or policy of NIE, and no official endorsement should be inferred. Experiment $I$ is based on research conducted by the first author in partial fulfillment of the requirements for the Master's degree. The first author is grateful to Lauren B. Resnick and Herbert Simon who, with his coauthors, supervised this research as members of his thesis committee. The authors also wish to thank the participating students, their teachers, and Maria E. Magone for her assistance in conducting Experiment $\mathrm{I}$. of complex problem-solving skills from simpler skills. Gagne's (1970) notion of hierarchies of learning has suggested that there is an optimal order for learning skills. Likewise, investigations of children's intellectual development and education (e.g., Resnick, 1973; Wang, Resnick, \& Boozer, 1971) have emphasized that successful performance in complex intellectual tasks requires proficiency in simple component tasks. More recently, Glaser and Resnick (1972) and Resnick and Glaser (in press) have suggested that the ability to assemble lower order skills into higher order competencies is a major determinant of one's intellectual capacity. They point out that computer simulations can be utilized as rigorous task analyses in guiding investigations of such assembly behaviors. A subsidiary focus of the present study was to observe whether subjects, given training on the lower order subroutines of a computer simulation, could assemble them into the higher order routines for which they were prerequisite.

The task selected for study was the letter series completion problem, some examples of which appear in Table 1. This sort of problem, commonly found on intelligence tests, was used by Thurstone and Thurstone (1941) in their studies of intelligence. More recently, performance on this task has been investigated in computer simulation studies. Simon and Kotovsky (1963) and Kotorsky and Simon (1973) have provided what is probably the most intensively analyzed computer simulation of letter series completion problems. However, Kotovsky and Simon (1973) pointed out that their theory of letter series completion performance consists of "a set of hypotheses about the characteristics of human behavior in this task" (p. 400). These hypotheses provided the basis for the training study reported here. 
Table 1

Matched Pairs of Letter Series Completion Problems Numbered According to Order of Occurrence on Pretest and Posttest

\begin{tabular}{|c|c|c|c|}
\hline $\begin{array}{l}\text { Pretest } \\
\text { Problem } \\
\text { Number }\end{array}$ & Problem & $\begin{array}{l}\text { Posttest } \\
\text { Problem } \\
\text { Number }\end{array}$ & Problem \\
\hline 1 & cdcded & 3 & xyxyxy \\
\hline 2 & aaabbbcccdd & 6 & hhhiiijijkk \\
\hline 3 & pononmnmlmlk & 13 & dcbcbabaz \\
\hline 4 & rscdstdetuef & 2 & efpqfgqrghrs \\
\hline 5 & npaoqapraqsa & 7 & acmbdmcemdfm \\
\hline 6 & wxaxybyzczadab & 12 & hilijmiknklolm \\
\hline 7 & abmcdmefmghm & 11 & ghrijrklrmnr \\
\hline 8 & defgefghfghi & 5 & klmnlmnomnop \\
\hline 9 & mabmbcrncdm & 1 & aopapqaqra \\
\hline 10 & urtustuttu & 15 & mjlmklmllm \\
\hline 11 & $q \times a p x b q x a$ & 9 & tadsaetad \\
\hline 12 & abyabxabwab & 10 & hifhiehidhi \\
\hline 13 & atbataatbat & 4 & piqpippiqpi \\
\hline 14 & aduacuaeuabuaf & 8 & gjagiagkaghagl \\
\hline 15 & jkqrklrslmst & 14 & cdjkdekleflm \\
\hline
\end{tabular}

Kotovsky and Simon's computer simulation was based on the performance of adolescents and adults. A further goal of this study was to assess the applicability of that model to children's performance on letter series completion problems and to search for developmental differences within a sample of elementary school children. Consequently, a variety of age groups was included in this study. The features of problems which yielded the most difficulty for the adolescents and adults examined by Kotovsky and Simon were compared with the obstacles encountered by the children.

\section{KOTOVSKY AND SIMON'S MODEL}

Kotovsky and Simon's (1973) simulation requires four basic subroutines for correct solution: (a) the detection of interletter relations; (b) the discovery of periodicity; (c) the completion of a pattern description; (d) extrapolation. Subjects in this study were trained on the first two of these four subroutines.

\section{Detection of Interletter Relations}

Kotovsky and Simon point out that subjects could solve all the Thurstone series completion problems in Table 1 using three relations: identity, next, and backwards next. An identity relation occurs between letters that are alike. For example, there is an identity relation between the ms in the series abmcdmefm .... A next relation occurs between letters standing in alphabetical order. In the series urtustuttu..., next relates the second, fifth, and eighth letters because $r, s$, and $t$ occur in the same order in adjacent positions of the alphabet. A backwards next relation exists between letters standing in a reversed alphabetical order. There is a backwards next relation between every third letter, starting with $y$, in the series abyabxabwab ....
Discovery of Periodicity

The period length of a series is the regular interval at which a relation or a break in a relation occurs. For instance, the series aabbbcccdd ..., displays a break in the identity relation every three letters. Therefore, the period length of that series is three. Alternatively, the same period length could be discovered by noticing that a next relation exists between every third letter of this series. Kotovsky and Simon's model utilized both of these ways of discovering periodicity. Consequently, subjects in this study were trained to discover periods both by finding regularly occurring breaks in a given relation and by searching for relations occurring at a fixed interval.

\section{Completion of the Pattern Description}

The third process in Kotovsky and Simon's simulation is the completion of the pattern description. This component involves the assembly of information about the interletter relations and the periodicity of the series into a succinct rule governing the generation of the entire series. For instance, to complete the series cdcdcd ..., it is not sufficient to find some occurrences of the identity relation and to recognize that the periods are two letters in length. The information obtained by applying the relations and periodicity subroutines must be assembled into a cule that assigns a definite relation to each position of each period. Thus, for the sequence cdcdcd..., the subject must formulate the rule that the first letter of every period is related to the first letter in each of the other periods by identity and that the second letters of all periods are also related by identity. The second aspect of this study, subjects' capacity to integrate lower order subskills into a higher order competency, was investigated by omitting instruction on the completion of pattern descriptions. In this way, if the higher order skill emerged in the subjects' solutions, it could be attributed to the capability of the subjects to assemble the subskills that they had learned in training. This capability may vary as a function of developmental level.

\section{Extrapolation}

The fourth process involved in the solution of letter series completion problems is extrapolation. To extrapolate, the subject must hold his pattern description in memory and use this rule to continue the generation of the series. No training was given on this component, since it would be difficult to teach methods for extrapolating without first giving instruction on pattern descriptions. In addition, the ability to extrapolate may be largely predetermined by the individual's work ing memory capacity and strategies.

\section{EXPERIMENT 1}

\section{Method}

Materials. Experiment I employed the two sets of letter series 
completion problems displayed in Table 1 . The first set contained problems identical to those used by Kotovsky and Simon; this set constituted a pretest. The second set, which made up a posttest, was derived from the pretest by initializing the problems at different places in the alphabet. Thus, the essential structures of the two sets did not differ.

The tests were typed on $81 / 2 \times 11$ in. sheets of paper, with seven or eight problems per page. A cassette tape recorder was placed beside the subject to record any remarks he made during testing. In addition to the pretest and posttest, experimental subjects received a booklet with intervening training exercises.

Subjects and experimenters. Subjects were randomly selected from Grades 1 to 6 of a local school. A female graduate student and the first author served as Experimenters 1 and 2, respectively.

Procedure and design. Subjects were pretested, and those subjects who made mistakes on at least 8 of the 15 problems were retained in the study. Six subjects who performed at or below this criterion were obtained from each grade, while zero, one, three, two, four, and eight subjects from Grades 1 through 6 , respectively, were rejected for failing on fewer than eight problems. Within grades, three subjects were randomiy assigned to the experimental group and three to the control group.

Control subjects took the pretest and received the posttest 1 or 2 days later. Between the pretest and the posttest, experimental subjects were trained on the relations and periodicity components of Kotovsky and Simon's simulation. The training was carefully designed to effect a correspondence between the abilities of the subjects and the subroutines of the simulation. In all, this instruction required approximately four $1 / 2-h$ sessions.

Each subject was individually tested and trained (if the subject was in the experimental condition) by the same experimenter. One subject within each grade and treatment condition was randomly assigned to Experimenter 1 and two subjects within each grade and treatment condition to Experimenter 2. Subjects were encouraged to think aloud as they tried to complete the series.

Relations training. The first component taught was the detection of relations between letters of the series. Two kinds of instruction were used to teach the three interletter relations. In the first type of training, a subject was presented with four typed pairs of letters. He was to circle the "odd" pair, or the pair that did not exhibit a relation common to the other three pairs. The experimenter immediately corrected the subject's response and then proceeded to name and define the interletter relation displayed by the three pairs.

The second type of relations training exercise gave subjects experience in detecting occurrences of a given interletter relation in a line of several typed letters. For example, the subject was asked to draw lines connecting all letters related by next in this letter string: $\mathrm{z} \mathrm{c} \mathrm{f} \mathrm{f} \mathrm{lm} \mathrm{p} \mathrm{n} \mathrm{r} \mathrm{s} \mathrm{w.} \mathrm{The} \mathrm{solution}$ to this training exercise is the following:

$$
\text { zcdfal } \underbrace{\operatorname{mpn} \mathrm{us}} \text { w. }
$$

When errors were made, the experimenter corrected them and demonstrated a systematic left-to-right procedure for finding all instances of the required relation.

Discovery of periodicity. In separate training sessions, experimental subjects were taught to discover periods both by finding regularly occurring breaks in a given relation and by searching for relations occurring at a fixed interval. Strings of letters were presented, and subjects were instructed to mark off the periods of the strings with slashes. The following example displays such an exercise, with correctly placed slashes marking off the periodic structure: a a $\mathrm{a} / \mathrm{x} \times \mathrm{x} / \mathrm{m} \mathrm{m} \mathrm{m}$. In this exercise, the periods could be found by noticing the break in the identity relation that occurs every three letters. In the following exercise, the subject must recognize repeated instances of the identity relation at three-letter intervals, beginning with the first $\mathrm{m}$ : $\mathrm{m} \mathrm{k} \mathrm{f} / \mathrm{m} \mathrm{t} \mathrm{z/m} \mathrm{b} \mathrm{d}$. Following the subject's attempt to discover the periods, the experimenter corrected the subject and explained the basis for the periodic structure of the sequence.

Independent training of subskills. As mentioned earlier, one objective of this study was to investigate the integration of lower order subskills into higher order processes. In order that assembly of these subskills could be attributed to the subject rather than to an instructional confounding of the components, the component subskills were taught independently of each other. No letter strings used to illustrate relations possessed a periodic structure, and none of the letter strings employed to teach about periods were fully extrapolatable.

\section{Results and Discussion}

In all, 54 subjects took the pretest, 36 of whom made mistakes on at least 8 of the 15 problems. Two experimental subjects from Grade 1 failed to complete training, so their performance does not contribute to the data that follow. Subjects generally spent about $1 / 2 h$ on each of the tests.

Analysis of problem characteristics. Before discussing the effects of teaching the subroutines, the Kotovsky and Simon model must be assessed in terms of its applicability to the competencies of the children in this sample. If the model's assertions about difficult problem features were inconsistent with the obstacles actually encountered by the children, then there would be little reason to expect improvement of test scores as a function of training on the subroutines of the model.

Problem difficulty. Perhaps the best basis for performance comparisons between the computer model, the adolescent and adult samples on which the model was based, and the sample of children used here is the pattern description notation developed by Kotovsky and Simon. This notation represents the pattern description rules generated by Kotovsky and Simon's subjects and by the computer in completing letter series problems. The relations, the periodic structure, and the working memory requirements associated with each problem are specified in this notation (see Kotovsky \& Simon, 1973, Table 4). In general, Kotovsky and Simon found that the more characters they required to notate a pattern, the more difficulty subjects experienced in solving that problem.

The Spearman rank order correlation $\left(\mathrm{r}_{\mathbf{s}}\right)$ between the lengths of the pattern descriptions (number of characters) and the number of errors made by experimental subjects on the 15 pretest problems was .789 , $\mathrm{df}=13, \mathrm{p}<.001$; for control subjects this correlation was $.773, p<.001$. Thus the children experienced difficulty levels on the problems quite similar to the ordering predicted by Kotovsky and Simon. In fact, the Is value for these children compared quite favorably with the rank order correlation of $.802, p<.001$, obtained from a group of high school students whose performance was measured by Kotovsky and Simon. Apparently, the random assignment of subjects to 
Table 2

Number of Blanks Unambiguously Classified According to Relations and Positions

\begin{tabular}{lccrr} 
& \multicolumn{3}{c}{ Position } \\
\cline { 2 - 4 } Relation & Beginning & Middle & End & $\Sigma$ \\
\hline Identity & 9 & 3 & 10 & 22 \\
Next & 5 & 7 & 8 & 20 \\
Backwards Next & 0 & 2 & 3 & 5 \\
$\Sigma$ & 14 & 12 & 21 & 47 \\
\hline
\end{tabular}

treatment conditions resulted in samples that were equivalent with respect to their distributions of relative problem difficulty. The error distributions for the 15 pretest problems were highly correlated between the two treatment conditions, $\mathrm{r}_{\mathrm{S}}=.960, \mathrm{p}<.001$.

Relations and positions within periods. Another basis for comparing Kotovsky and Simon's observations with the performance of the children in this study is the degree of difficulty posed by the various interletter relations. Kotovsky and Simon indicated that the next relation added more difficulty to problems than did identity. The present experiment confirmed that assertion: A significantly greater percentage of errors was produced in blanks requiring the next relation $(71.76 \%)$ than in blanks requiring identity $(32.50 \%)$, $\mathrm{F}(1,28)=273.08, \mathrm{p}<.001$.

An additional possible source of problem difficulty, not examined by Kotorsky and Simon, is the position of a blank within a period. For example, slashes display

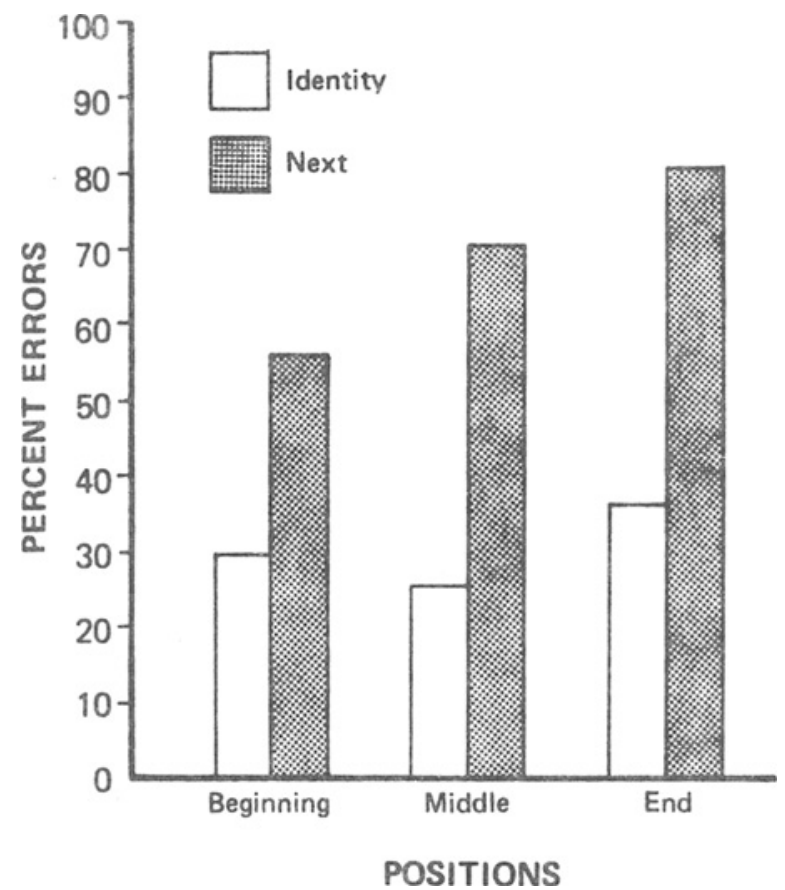

Figure 1. Error percentages according to relations and positions averaged across treatments and tests. (Grade 1 subjects excluded.) the periodic structure of the following problem: $\mathrm{m} \mathrm{a} \mathrm{b} / \mathrm{m} \mathrm{b} \mathrm{c} / \mathrm{m} \mathrm{c} \mathrm{d} / \mathrm{m}-\ldots 1 \ldots$. The first blank occupies the middle position of the fourth period, and the second blank occupies the last position of that period. The letter that is placed in the third blank will begin the fifth period; the fourth blank, in turn, occupies the middle position of that period.

To examine the positions factor and its possible interactions with relations, each blank of every pretest and posttest problem was classified according to its position within the period and according to the type of relation needed to correctly complete that blank. More than one relation could be used to correctly complete 13 out of the 60 blanks within each test. Those blanks were eliminated from consideration, and the resulting classification of blanks is shown in Table 2. For series problems with two letters per period, no blanks were classified as occupying a middle position. For series problems with more than three letters per period, all the intermediate positions were classified as middle.

There were only five instances of the backwards next relation, none of which occurred in the beginning position. Consequently, that relation was eliminated from the analysis of relations and positions that follows. Since only one first-grade subject completed training, data from Grade 1 were eliminated to further simplify the analysis. Due to the different cell frequencies in Table 2, subjects were scored for the percentage of blanks that were incorrectly filled for each relationposition combination. Those error percentages can be seen graphically in Figure 1. An analysis of variance performed on treatments, tests, relations, and positions indicated a main effect of positions, $F(2,56)=26.99$, $\mathrm{p}<.001$, in addition to the previously reported relations effect. Scheffe contrasts on the positions effect indicated that the beginning position (39.52\% errors) was significantly easier than either the middle $(57.50 \%$ errors) or end $(56.57 \%$ errors) positions, $\mathrm{Fs}(1,56)>17$, ps $<.001$.

A significant Relations by Positions interaction was obtained, $F(2,56)=13.69, p<.001$. An analysis of simple main effects indicated that identity was easier than next in all positions, $\operatorname{Fs}(1,84)>76$, ps $<.001$. There was a significant effect of positions for blanks requiring the next relation, $F(1,112)=26.96, p<.001$, but not for blanks requiring identity, $F(1,112)=1.73$. Apparently, the identity relation was so easy to work with that it was not nearly as sensitive to the influence of positions as was the next relation.

As expected, the analysis of variance also revealed a main effect of tests, $F(1,28)=26.01, p<.001$, with subjects performing better on the posttest than on the pretest.

Main effect of training. Table 3 shows the means and standard deviations for the number of incorrectly filled blanks on the pretest and posttest according to grade and treatment condition. In order to assess the amounts of improvement shown by subjects relative to their 
respective baseline performances, each of the 34 subjects who completed the posttest was scored for percentage decrease in errors from pretest to posttest. An unequal-n three-way analysis of variance (least squares solution) with treatments, experiments, and grades as variables indicated a significant effect only for treatment conditions, with the experimental group being significantly superior to the control group, $F(1,27)=3.97, p<.03$, one-tailed. Experimental subjects demonstrated a $31.93 \%$ reduction in errors, while control subjects decreased errors by $13.42 \%$. Although instruction on the subroutines of the simulation resulted in significantly greater improvement for the experimental subjects than for the controls, even the smaller gain made by the control group was significant, $t(27)=2.23$, $\mathrm{p}<.03$, one-tailed.

Developmental effects. No significant grade effect was found in the preceding analysis of the percentage decrease in errors on the posttest relative to the baseline pretest performance. Thus, age did not affect subjects' ability to improve from pretest to posttest. However, within any given test (i.e., pretest or posttest), the older subjects performed better than the younger ones. An additional analysis of variance of errors, which included Treatments, Tests, and Grades as factors, indicated a main effect of grades, $F(4,20)=3.38$, $p<.05$, but no interactions with grades.

Generality of training effects. Given the quantitative differences in improvement between treatment conditions, an interesting question is whether there were also qualitative differences in the types of problems on which the two groups improved. To answer this question, pairs of pretest and posttest problems, matched in pattern descriptions, were rank ordered in terms of the absolute improvements made from pretest to posttest. This was done separately for both treatment groups. Although the two treatments had demonstrated similar distributions of problem difficulty on the pretest, their distributions of pretest to posttest improvements were not at all similar, $\mathrm{r}_{\mathrm{s}}=$ $-.201, \mathrm{p}>.10$.

This lack of relationship between treatment groups in loci of improvements required further consideration. A taxonomy of problems was developed to delineate the similarities and differences in improvements between treatment conditions. For each subject in each condition the 15 pairs of matched pretest-posttest problems were divided into three classes: (a) pairs in which an individual made no pretest errors (perfect problems); (b) pairs in which no more than one pretest error was made (easy problems); (c) pairs in which two or more pretest errors were made (difficult problems). Since no improvement was possible in perfect problems, those problems were not considered in the analyses that follow.

A chi-square test on easy problems revealed no signifi-
Table 3

Number of Errors on Pretest and Posttest by Grade (Gr) and Treatment Condition

\begin{tabular}{|c|c|c|c|c|c|}
\hline & & \multicolumn{2}{|c|}{ Experimental } & \multicolumn{2}{|c|}{ Control } \\
\hline & & Pretest & Posttest & Pretest & Posttest \\
\hline Gr 1 & $\begin{array}{l}\text { Mean } \\
\text { SD }\end{array}$ & $\begin{array}{c}34.00 \\
0^{*}\end{array}$ & $\begin{array}{c}28.00 \\
0^{*}\end{array}$ & $\begin{array}{r}50.33 \\
4.96\end{array}$ & $\begin{array}{r}49.00 \\
5.89\end{array}$ \\
\hline Gr 2 & $\begin{array}{l}\text { Mean } \\
\text { SD }\end{array}$ & $\begin{array}{r}47.33 \\
4.68\end{array}$ & $\begin{array}{r}38.33 \\
6.15\end{array}$ & $\begin{array}{r}49.33 \\
1.79\end{array}$ & $\begin{array}{r}42.66 \\
4.56\end{array}$ \\
\hline Gr 3 & $\begin{array}{l}\text { Mean } \\
\text { SD }\end{array}$ & $\begin{array}{l}41.33 \\
10.64\end{array}$ & $\begin{array}{l}28.33 \\
13.60\end{array}$ & $\begin{array}{r}37.33 \\
5.46\end{array}$ & $\begin{array}{l}33.33 \\
14.35\end{array}$ \\
\hline Gr 4 & $\begin{array}{l}\text { Mean } \\
\text { SD }\end{array}$ & $\begin{array}{r}31.66 \\
8.75\end{array}$ & $\begin{array}{l}27.66 \\
17.92\end{array}$ & $\begin{array}{l}42.33 \\
13.48\end{array}$ & $\begin{array}{l}33.66 \\
11.97\end{array}$ \\
\hline Gr 5 & $\begin{array}{l}\text { Mean } \\
\text { SD }\end{array}$ & $\begin{array}{r}33.66 \\
6.83\end{array}$ & $\begin{array}{l}22.66 \\
14.53\end{array}$ & $\begin{array}{r}31.66 \\
5.47\end{array}$ & $\begin{array}{r}22.66 \\
9.19\end{array}$ \\
\hline Gr 6 & $\begin{array}{l}\text { Mean } \\
\text { SD }\end{array}$ & $\begin{array}{r}29.33 \\
6.25\end{array}$ & $\begin{array}{r}12.66 \\
6.81\end{array}$ & $\begin{array}{r}26.33 \\
2.66\end{array}$ & $\begin{array}{r}26.33 \\
2.90\end{array}$ \\
\hline
\end{tabular}

*This standard deviation (SD) is zero, since only one first-grade subject contributed to this cell.

cant difference between treatment groups in the frequencies of improvement, no change, or a decrease in score from pretest to posttest, $\chi^{2}(2)=1.23$. However, for difficult problems, the experimental subjects showed a much greater tendency than controls to reduce mistakes by more than one error per problem, $\chi^{2}(3)=$ $17.12, \mathrm{p}<.001$.

It appears that the training given to experimental subjects provided them with a systematic technique that could be repeatedly applied and thus lead to larger error reductions on difficult problems than those shown in the control condition. The conclusion that the experimental subjects had acquired a sophisticated information management technique was further supported by the fact that experimental subjects demonstrated perfect posttest solutions to difficult problems significantly more often than control subjects, $\chi^{2}(1)=12.55$, $\mathrm{p}<.001$.

Interaction of treatments with relations. A final distinction between the improvement patterns of the two treatment conditions was revealed by the previously reported analysis of variance performed on treatments, tests, relations, and positions. A significant Treatments by Tests by Relations interaction, $F(1,28)=5.05$, $\mathrm{p}<.05$, showed that the difference between treatment groups in extent of improvement could be localized in blanks requiring the next relation. For the identity relation, experimental subjects reduced errors by $30.70 \%$, while the control group reduced errors by $34.97 \%$. On the other hand, experimental subjects demonstrated a $33.60 \%$ decrease in errors for blanks requiring a next relation, while controls showed only a $10.55 \%$ reduction. Apparently, training revealed its largest effects where it was most needed-with difficult problems and with the more difficult interletter relation. 


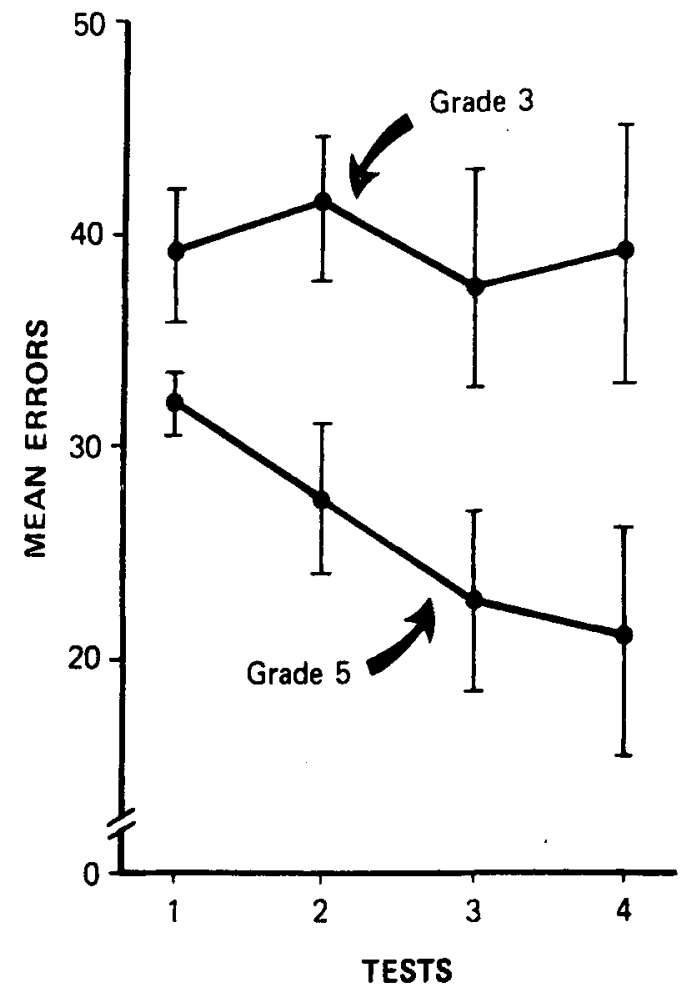

Figure 2. Means and standard deviations of errors. (Maximum possible errors per subject per test $\mathbf{= 6 0}$.)

\section{EXPERIMENT II}

Experiment I indicated that the experimental group's improvement surpassed that of the control group by a factor of $2 \frac{1}{2}$ to 1 . Yet the control group made significant gains in spite of the fact that its participation was limited to the two tests, while the experimental group received additional practice on the subskills identified by the simulation. An important question is whether the performance of the control group would more closely approximate that of the experimental group if control subjects were given more practice on letter series problems.

There might also be developmental differences in the extent to which improvement requires explicit instruction on the subskills, as opposed to simple practice on the problems per se. In the memory literature, research on production deficiency (e.g., Flavell, Beach, \& Chinsky, 1966; Moely, Olson, Halwes, \& Flavell, 1969) has demonstrated that young children often require explicit instruction in order to utilize mediators and thus improve their recall. Older children, on the other hand, have been shown to spontaneously generate such mediators. Perhaps there is a similar Treatment by Age interaction for series completion problems. To investigate these possibilities, a second control group was added to the study. Subjects in two age groups received two extra sets of letter series completion problems between the pretest and posttest.

\section{Method}

Materials. The materials were identical to those used by the control group in Experiment $I$ except for the addition of two more sets of letter series completion problems matched in structure to the pre- and posttest problems.

Subjects. Since many students at the school used in Experiment I had participated in that experiment or in earlier pilot studies, subjects for Experiment II were drawn from a second, local, elementary school. Children were randomly selected from Grades 3 and 5 . The first author served as the experimenter.

Procedure and design. To make the samples of Experiments 1 and II as comparable as possible, subjects were retained only if they made mistakes on at least 8 of the 15 problems and scored less than one standard deviation from the mean pretest score for Experiment I subjects in the corresponding grade. In addition, to insure some minimum understanding of the basic task requirements, only those subjects who performed errorlessly on at least two pretest problems were included in the sample. Using these criteria, 6 subjects from each of the two grades were retained in the experiment, while 15 subjects from Grade 3 and 4 subjects from Grade 5 were eliminated. Due to the impending termination of the school year, one third-grade student had to be included whose pretest scote was not quite within a standard deviation of the earlier sample's mean. This subject made 29 pretest errors, while the number of pretest errors made by Grade 3 subjects across treatment conditions in Experiment $I$ was 39.33, with a standard deviation of 8.67. Grade 5 subjects across treatments in Experiment I averaged 32.67 pretest errors, with a standard deviation of 6.24 .

Each subject completed a new letter series test every day or two until he finished all four tests. To maintain subjects' interest in the experiment, after each test the subject and experimenter played with toys, games, or jigsaw puzzles. None of these activities involved any sort of letter series completion skills.

\section{Results and Discussion}

In all, 31 subjects were pretested, 12 of whom were retained in the experiment. Generally, the subjects spent 20-30 min working on each set of problems.

Comparability of samples. As mentioned in the preceding section, the selection procedure was designed to include subjects in Experiment II who were similar to the sample chosen for the first experiment. A Spearman rank order correlation between samples for relative pretest problem difficulty indicated that the samples were, in fact, comparable, $r_{\mathrm{s}}=.97, \mathrm{p}<.001$. In addition, the pretest performance of the subjects in Experiment II was highly consistent with the predictions of problem difficulty made by Kotovsky and Simon, $\mathrm{r}_{\mathrm{S}}=.74$, $\mathrm{p}<.005$.

Age effects on improvement. Figure 2 displays subjects' performance across the four tests. An analysis of variance with grades and tests as variables indicated that subjects improved with age, $F(1,10)=7.78, p<$ .03 , and across tests, $F(3,30)=5.60, p<.005$. The improvement over the four tests was linear, $F(1,30)=$ $14.96, \mathrm{p}<.001$, with no significant departure from linearity.

In addition, there was a significant Grades by Tests interaction, $F(3,30)=3.76, p<.03$. A test of simple main effects indicated no significant differences between grades on the pretest, $F(1,40)=1.73$, but significant differences in favor of the older subjects on the remain- 
ing three tests, $\operatorname{Fs}(1,40)>6.89$, ps $<.03$. Ninety per. cent of the Grades by Treatments interaction was accounted for by differences between grades in the linear trend across tests, $\mathrm{F}(1,30)=10.18, \mathrm{p}<.005$.

These results indicate that older subjects could demonstrate large improvements in score simply as a function of practicing series completion problems. Younger subjects, however, did not share this capacity. Apparently, explicit instruction was a prerequisite for improvement among younger children.

\section{GENERAL DISCUSSION}

\section{Psychological Utility of the Simulation}

Experiment $I$ indicated that the subroutines of a computer simulation could be translated into subskills that were instructable to children. Although the total time spent in training amounted to only about $2 \mathrm{~h}$, the effects of training were noticeably facilitative. Thus, the cognitive processes hypothesized by Kotovsky and Simon's computer simulation have been shown to be quite compatible with the problem-solving activities of the children in this study.

As mentioned previously, subjects were not taught to integrate the trained relations and periodicity subskills into a coherent rule that described the pattern of the series. There was an interest in whether subjects could spontaneously execute this assembly process. To the extent that subjects demonstrated improved performance on the posttest following training on the individual components of those problems, it appears that subjects were capable of organizing the independently taught subskills to produce better performance on the task as a whole. However, further work needs to be done to reveal the precise nature of the assembly process and the conditions which promote and inhibit its execution.

\section{Posttest Errors Following Training}

While training yielded substantial improvements in scores, experimental subjects continued to make some mistakes. In this regard, one aspect to consider is that only a relatively brief length of time was devoted to training subjects on the detection of interletter relations and the discovery of periodicity. Perhaps if subjects had received more drill on these subskills, posttest solutions would have improved further.

Second, as mentioned in the preceding section, subjects were not taught how to organize the features they induced from the series into coherent pattern descriptions, although this was a subroutine of Kotovsky and Simon's simulation. While subjects seemed to demonstrate some capacity for assembling these features into a higher order rule describing the whole series, training on this assembly process might have further augmented experimental subjects' solutions. A study of short-term memory capacity in retardates by Butterfield, Wambold, and Belmont (1973) lends support to this suggestion. They discovered that retardates' short-term memory handicaps were largely produced by an inability to access and coordinate existing memory processes. Butterfield et al. suggest that a process of coordination, or assembly, might well be trainable and that such instruction could facilitate performance more than training on any of the lower order subskills. Resnick and Glaser (in press) indicate some of the variables contributing to children's difficulty in executing the assembly process.

Finally, subjects were not instructed on the extrapolation component of the computer model. Kotovsky and Simon pointed out that the most frequent errors they observed were incorrect extrapolations of appropriate pattern descriptions. Thus, it is likely that some of the errors made by the experimental subjects stemmed from an overloading of working memory when an attempt was being made to generate letters from a correct pattern description. In fact, on a number of occasions in Experiments I and II, subjects were observed to correctly verbalize the pattern description for a series and then become confused as they tried to utilize that rule to complete the blanks.

\section{Developmental Issues}

The preceding section suggested that solution performance is strongly influenced by one's capacity for correctly retaining and utilizing a pattern description while generating letters for the blanks. Presumably, younger children have a more limited working memory capacity than do older children (Pascual-Leone, 1970). This memory difference may have been responsible for the continued superiority of the older subjects over younger ones even after training on the component skills suggested by the simulation.

Experiment I suggested that a small amount of practice on letter series completion problems, without instruction, could lead to slight, but significant, gains in performance. Experiment II examined this issue more closely and indicated that, with additional practice on letter series completion problems, older subjects could improve their scores by an amount comparable to that displayed by experimental subjects in Experiment $I$. Younger subjects, however, were unable to benefit from simple practice. Yet, as demonstrated in the first experiment, subjects of all ages could profit from instruction on the component processes suggested by the simulation.

Perhaps the basis for this age difference can be found in Tulving and Pearlstone's (1966) distinction between the availability and the accessibility of information in memory. Quite possibly, the older subjects in Experiment II had acquired information relevant to series completion at some time prior to the presentation of the pretest. This information was thus available to them, and, as they took progressively more tests, the series completion problems cued the previously learned skills, thus leading to improved solution performance. 
The younger children, however, may not have acquired the skills needed to correctly complete series, or may have acquired them in very primitive forms. As a result, the necessary subskills were neither available or accessible to those subjects on any of the tests. Training was required to place the relevant information at the disposal of the younger subjects.

\section{Experimental-Psychometric Investigation of Intelligence}

The present study can be offered as a response to suggestions recently made by Glaser (1972), Hunt, Frost, and Lunneborg (1973), and Estes (1974) that investigations of intellectual functioning should combine the contributions of the psychometrician with those of the experimental psychologist. Glaser has rather clearly identified a stumbling block to many of the best efforts of psychologists examining human intelligence: "Tests of general ability, intelligence, and aptitude follow the accepted practice of attempting to predict the outcomes of learning in our rather uniform educational programs .... They are not designed to determine the different ways in which different students learn best, to measure the basic processes that underlie different kinds of learning, nor to assess prerequisite performance capabilities required for learning a new task" (Glaser, 1972, p. 7).

Both Hunt et al. and Estes have emphasized the need to experimentally study the types of tasks found on intelligence tests. They have suggested that such research could reveal the cognitive processes required for skillful performance in those tests. At the same time, since such tests have predictive validity, the experimental analyses might suggest trainable psychological processes that could facilitate academic achievement. This study specifically focused on teaching processes identified by a computer simulation which were hypothesized components of an intelligence test task. Consequently, this study supported the psychological reality of the identified processes and suggested the potential of instruction in these processes for improving intellectual competence.

\section{REFERENCES}

Butterfield, E. C.. Wambold, C., \& Belmont, J. M. On the theory and practice of improving short-term memory. American Journal of Mental Deficiency, 1973, 77, 654-669.

Estes, W. K. Learning theory and intelligence. American Psychologist, 1974. 29, 740-749.

Flavell. J. H., Beach, D. H.. \& Chinsky, J. M. Spontaneous verbal rehearsal in a memory task as a function of age. Child Development, 1966, 37, 283-299.

GAGNÉ, R. M. The conditions of learning. New York: Holt, Rinehart. \& Winston. 1970.

GLASER. R. Individuals and learning: The new aptitudes. Educational Researcher, 1972, 1, 5-13.

GlASER, R., \& RESNICK, L. B. Instructional psychology. In P. H. Mussen \& M. R. Rosenzweig (Eds.), Annual Review of Psychology, 1972, 23, 207-276.

Hunt, E., Frost, N.. \& Lunneborg. C. Individual differences in cognition: A new approach to intelligence. In G. H. Bower (Ed.). The psychology of learning and motivation: Advances in research and theory (Vol. 7). New York: Academic Press. 1973.

Kotovsky, K., \& Simon, H. A. Empirical tests of a theory of human acquisition of concepts for sequential patterns. Cognitive Psychology, 1973, 4, 399-424.

Moely, B. E., Olson, F. A., Halwes, T. G., \& Flavell, J. H. Production deficiency in young children's clustered recall Developmental Psychology, 1969, 1, 26-34.

PAsCuAl-LeONe, J. A mathematical model for the transition role in Piaget's developmental stages. Acta Psychologica, 1970, 32, 301-345.

REsNicK, L. B. (Ed.). Hierarchies in children's learning: A symposium. Instructional Science, 1973, 2, 311-362.

Resnick, L. B., \& Glaser, R. Problem solving and intelligence. In L. B. Resnick (Ed.), The nature of intelligence. Hillsdale, N.J: Erlbaum, in press.

Simon, H. A., \& Kotovsky, K. Human acquisition of concepts for sequential patterns. Psychological Review, 1963 70. 534-546.

Thurstone, L. L.. \& Thurstone, T. G. Factorial studies of intelligence. Chicago: University of Chicago Press, 1941.

Tulving, E., \& Pearlstone, Z. Availability versus accessibility of information in memory for words. Joumal of Verbal Leaming and Verbal Behavior, 1966, 5, 381-391.

W ANG. M. D., Resnick, L. B., \& Boozer, R. F. The sequence of development of some early mathematics behaviors. Child Development, 1971, 42, 1767-1778.

(Received for publication September 2, 1975; revision accepted October 21,1975 .) 